ARTICLE

Received 27 Jun 2014 | Accepted 19 Sep 2014 | Published 31 Oct $2014 \quad$ DOl: 10.1038/ncomms6322

\title{
Multiple enzymatic activities of ParB/Srx superfamily mediate sexual conflict among conjugative plasmids
}

Priyank Maindola1, Rahul Raina1, Parveen Goyal', Krishnamohan Atmakuri2 ${ }^{\dagger}$, Abhishek Ojha1, Sourabh Gupta ${ }^{1}$, Peter J. Christie ${ }^{2}$, Lakshminarayan M. Iyer ${ }^{3}$, L. Aravind ${ }^{3}$ \& Arulandu Arockiasamy ${ }^{1}$

Conjugative plasmids are typically locked in intergenomic and sexual conflicts with co-resident rivals, whose translocation they block using fertility inhibition factors (FINs). We describe here the first crystal structure of an enigmatic FIN Osa deployed by the proteobacterial plasmid pSa. Osa contains a catalytically active version of the ParB/Sulfiredoxin fold with both ATPase and DNase activity, the latter being regulated by an ATP-dependent switch. Using the Agrobacterium tumefaciens VirB/D4 type IV secretion system (T4SS), a relative of the conjugative T4SS, we demonstrate that catalytically active Osa blocks T-DNA transfer into plants. With a partially reconstituted T4SS in vitro, we show that Osa degrades T-DNA in the T-DNA-VirD2 complex before its translocation. Further, we present evidence for conservation and interplay between ATPase and DNase activities throughout the ParB/Sulfiredoxin fold, using other members of the family, namely P1 ParB and RK2 KorB, which have general functional implications across diverse biological contexts.

\footnotetext{
${ }^{1}$ Structural and Computational Biology Group, International Centre for Genetic Engineering and Biotechnology, Aruna Asaf Ali Marg, New Delhi 110067, India. 2 Department of Microbiology and Molecular Genetics, University of Texas Medical School at Houston, 6431 Fannin St, Houston, Texas 77030, USA.

${ }^{3}$ National Center for Biotechnology Information, National Library of Medicine, National Institutes of Health, 8600 Rockville Pike, Bethesda, Maryland $20894-$ 6075, USA. †Present address: Translational Health Science and Technology Institute, Gurgaon, Haryana 122016, India. Correspondence and requests for materials should be addressed to A.A. (email: sam@icgeb.res.in) or to L.A. (email: aravind@ncbi.nlm.nih.gov).
} 
$\mathrm{D}$ NA transfer systems, such as the subfamily of the type IV secretion systems (T4SSs) designated as the conjugation machines, play a major role in horizontal gene transfer and spread of fitness-enhancing adaptations in bacterial populations $^{1,2}$. During conjugation, a mobile DNA element is processed as a single-stranded transfer intermediate termed the T-strand or T-DNA, which is then delivered through the 'mating' channel to a recipient cell. The mating channel spans the donor cell envelope and is assembled from a dozen or more subunits, termed the 'mating pair formation' proteins (VirB1-VirB11), and a coupling factor (T4CP), VirD4, that serves to link the DNA substrate with the channel ${ }^{3-6}$. Majority of mobile genetic elements in Gramnegative bacteria encode conjugation systems composed of a core set of mating pair formation subunits and T4CPs bearing phylogenetic similarities to those of the VirB/VirD4 T4SS of Agrobacterium tumefaciens ${ }^{7}$. A. tumefaciens uses the VirB/VirD4 T4SS to deliver oncogenic T-DNA and protein effectors to plant cells to induce a tumorous growth termed crown gall disease $e^{8-10}$.

Conjugative plasmids are locked in genomic conflicts with other co-resident plasmids. Consequently, they often encode and deploy fertility inhibition factors (FINs) to selectively block conjugative transfer of 'rival' co-resident plasmids ${ }^{11-13}$. Among these poorly understood FINs, Osa, encoded by the IncW plasmid $\mathrm{pSa}$ is an oncogenic suppressor that renders the Ti plasmidcontaining A. tumefaciens nearly avirulent ${ }^{14,15}$. A homologous FIN, FiwA, encoded by plasmid RP1 (IncP $\alpha$ ), blocks the transfer of the co-resident plasmid R388 of incompatibility group IncW ${ }^{11}$. Studies to date have suggested that Osa blocks T-DNA and VirE2 transfer from Agrobacterium to the plant cell without affecting $\mathrm{T}$-strand generation or $\mathrm{VirB} / \mathrm{D} 4 \mathrm{~T} 4 \mathrm{SS}$ assembly ${ }^{16-18}$. However, molecular mechanisms underlying the action of Osa and homologous FINs remain unknown.

Hence, to elucidate the mechanism of action of Osa-like FINs, we first solved the crystal structure of Osa. This allowed functional characterization of the active site of Osa, which supports both ATPase and DNase activities. The model for Osa's action derived from these findings has far-reaching implications for diverse biological systems containing members of the ParB/ Srx superfamily.

\section{Results}

Osa structure and predicted active site. Osa crystals of $\mathrm{P} 4_{3} 2_{1} 2$ space group diffracted up to $1.75 \AA$. As structures of Osa's close relatives are unavailable, we solved its structure using the single anomalous dispersion method with $\mathrm{KAu}(\mathrm{CN})_{2}$ for phasing. The overall structure of Osa, refined to a final $R$ and $R_{\text {free }}$ of 19.7 and 23.9 , respectively (Table 1 ), contains a compact globular domain $(\sim 60 \times 40 \times 36 \AA)$ with six $\alpha$-helices, one $\eta$-helix $\left(3_{10}\right)$ and two $\beta$-sheets (Fig. 1a, Supplementary Fig. 1a). Structural comparison using DALI ${ }^{19}$ recovered human Sulfiredoxin (hSrx) and several ParB-like proteins $(Z \sim 4.5)$. Further visual examination of the topology confirmed that Osa belongs to the ParB/Srx superfamily. The conserved core ParB/Srx fold, including the version seen in Osa, is a distinctive structure with four strands and two helices (Fig. 1a,b, Supplementary Fig. 1b); $\beta 4-\alpha 2-3_{10}$ helix- $\alpha 3-\beta 6-\beta 7-\alpha 4-$ $\beta 8$. Of these, the second conserved helix $(\alpha 4)$ contains the arginine residue (R140), which is highly conserved throughout the ParB/Srx fold (Fig. 1c), with remaining conserved structural elements forming a ring around that helix (Fig. 1a). In addition, the extended linker between the first helix $(\alpha 2)$ and the $\beta$-hairpin $(\beta 6-\beta 7)$ in the core of the ParB/Srx fold has a small residue (usually proline; P117 in Osa) whose backbone carbonyl group forms a polar contact with the guanidino group of the conserved arginine to position it in a cavity reminiscent of an active site (Fig. 1a,d).
Table 1 | X-ray data collection and refinement statistics.

\begin{tabular}{|c|c|c|}
\hline Data collection & Native & $\begin{array}{l}\mathrm{KAu}(\mathrm{CN})_{2} \\
\text { derivative }\end{array}$ \\
\hline $\mathrm{X}$ ray wavelength $(\AA)$ & 1.5418 & 1.5418 \\
\hline Space group & $\mathrm{P}_{4}{ }_{3}{ }_{1} 2$ & $\mathrm{P} 4_{3} 2_{1} 2$ \\
\hline \multicolumn{3}{|l|}{ Cell dimensions $(\AA)$} \\
\hline$a, b, c(\AA)$ & $\begin{array}{c}60.87,60.87 \\
126.9\end{array}$ & $\begin{array}{l}61,61 \\
126.95\end{array}$ \\
\hline$\alpha, \beta, \gamma\left(^{\circ}\right)$ & $90,90,90$ & $90,90,90$ \\
\hline Resolution $(\AA)$ & 1.75 & 2.03 \\
\hline$R_{\text {merge }}$ total (final shell) $(\%)$ & $5.7(43.3)$ & $7.1(54.8)$ \\
\hline$I / \sigma \mid$ total (final shell) & $61.2(2.1)$ & $76.5(3.6)$ \\
\hline Completeness total (final shell) (\%) & $96.6(80.1)$ & $96.4(85.1)$ \\
\hline Redundancy & 25.8 & 46.2 \\
\hline \multicolumn{3}{|l|}{ Refinement } \\
\hline Resolution $(\AA)$ & 1.75 & 2.03 \\
\hline No. of reflections & 24,031 & 15,512 \\
\hline$R_{\text {work }} / R_{\text {free }}(\%)$ & $19.7 / 23.9$ & $19.1 / 23.5$ \\
\hline \multicolumn{3}{|l|}{ No. of atoms } \\
\hline Protein (non-H atoms) & 1,545 & 1,465 \\
\hline Gold (I) Cyanide ion & - & 9 \\
\hline Phosphates & 2 & 2 \\
\hline Isopropanol & 2 & - \\
\hline Glycerol & - & 3 \\
\hline Chloride ion & 1 & - \\
\hline Water & 111 & 108 \\
\hline B factor $\left(\AA^{2}\right)$ & 35.2 & 35.6 \\
\hline Protein (non-H atoms) & 34.8 & 35.1 \\
\hline Gold (I) Cyanide ion & - & 46.0 \\
\hline Phosphates & 42.4 & 40.0 \\
\hline Isopropanol & 43.7 & - \\
\hline Glycerol & - & 43.2 \\
\hline Chloride ion & 33.1 & - \\
\hline Water & 39.7 & 39.2 \\
\hline \multicolumn{3}{|l|}{ r.m.s. deviations } \\
\hline Bond lengths $(\AA)$ & 0.006 & 0.007 \\
\hline Bond angles $\left({ }^{\circ}\right)$ & 0.991 & 1.102 \\
\hline
\end{tabular}

Using structure-guided sequence alignment (Fig. 1c, Supplementary Fig. 1c), we identified four other residues of Osa, K100, D98, D136 and T139 that are highly conserved among other Osa-like FIN factors FiwA, and ICE1056Fin. Importantly, these five conserved residues, R140, K100, D98, D136 and T139, are located in close proximity around the axis of the second conserved helix $(\alpha 4)$ of the ParB/Srx fold in a charged pocket that is conserved throughout the superfamily (Fig. 1d). Hence, we hypothesized that this cavity is potentially the active site of Osa that is responsible for its FIN activity.

In vivo analysis of Osa. To demonstrate FIN activity of Osa in vivo, we used the agroinfiltration $\operatorname{method}^{20}$ to monitor T-DNA transfer through the Agrobacterium VirB/D4 T4SS into plant cells. To test the functional importance of the predicted active site of Osa in vivo, we generated osa-K100A, osa-R140A, osa-K100AR140A (Osa-KR) and osa-D98A-K100A-D136A-T139A-R140A (Osa-penta) mutants (Supplementary Tables 1 and 2). Native and mutant versions of Osa were co-transformed into Agrobacterium LBA4404 with a plasmid-borne GUS reporter bearing an intron. On agroinfiltration, the GUS reporter-based 
a
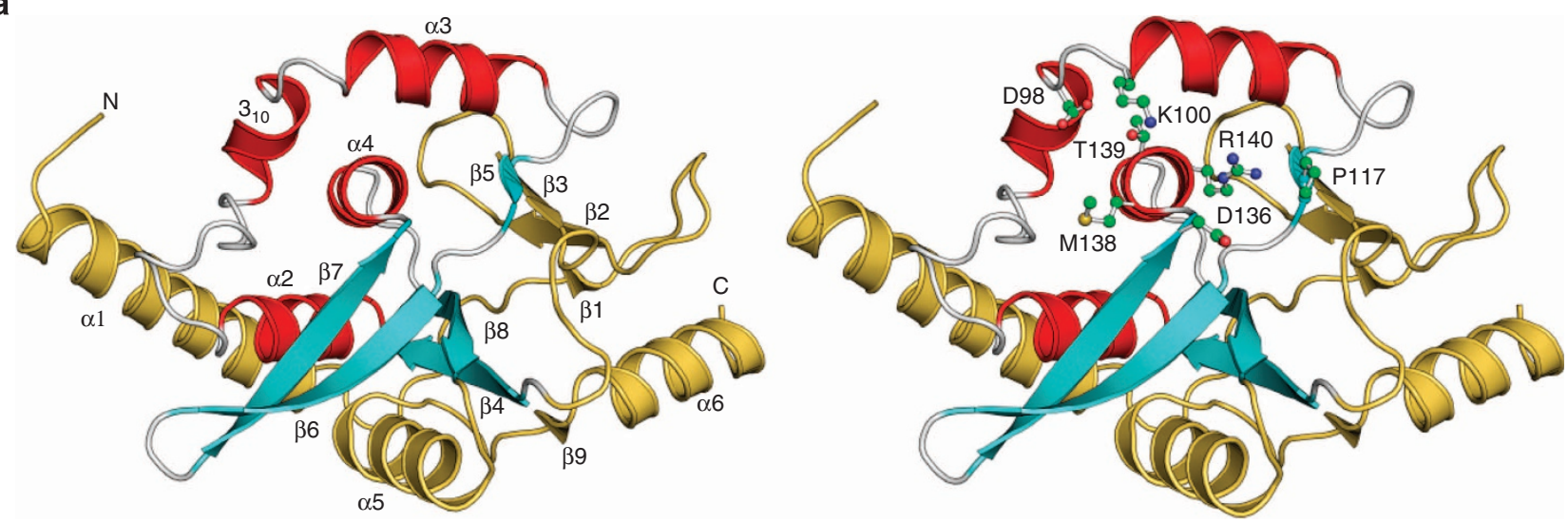

b
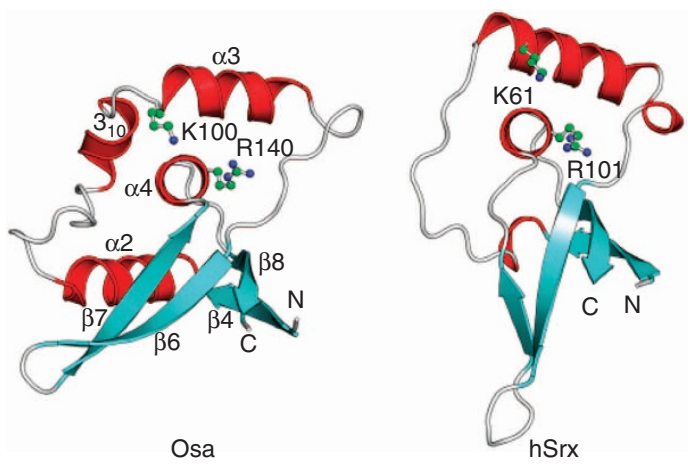

d
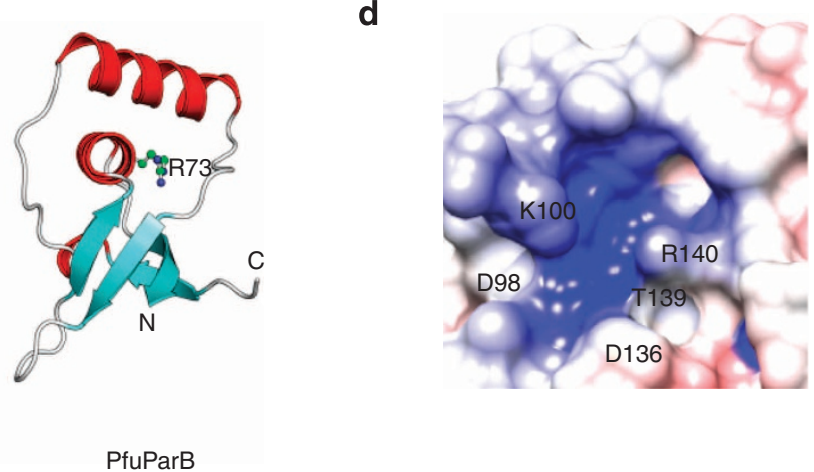

C

Secondary_structure
osa_Plasmid_pSa
fiwA_Plasmid_RP1
p1056.10c_H.influenzae
parB_Phage_P1
sopB_E.coli
dndB_S. lividans
SRXN1_H. sapiens(PDB:2rii)
WP_013814087.1_Serratia_sp.
ParB_P. furiosus (PDB:1vk1)
Atu1540_A.tumefaciens (PDB:2hwj)
ParB_T.thermophilus (PDB:1vzOF)
Spo0J_B. subtilis
korB_Plasmid_RK2
Consensus/75\%
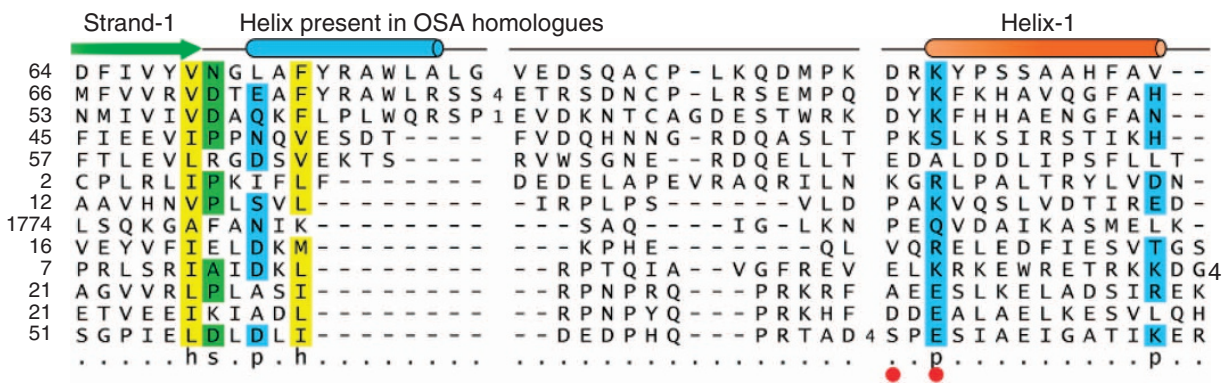

Secondary_structure

osa_Plasmid_pSa

fiwA_Plasmid_RP1

p1056.10c_H.influenzae

parB_Phage_P1

sopB_E.coli

dndB_S. lividans

SRXN1_H. sapiens (PDB:2rii)

WP_013814087.1_Serratia_sp

ParB__P. furiosus (PDB:1vk1)

Atu1540_A.tumefaciens (PDB:2hwj)

ParB_T.thermophilus (PDB:1vzOF)

Spo0J_B. subtilis

korB_Plasmid_RK2
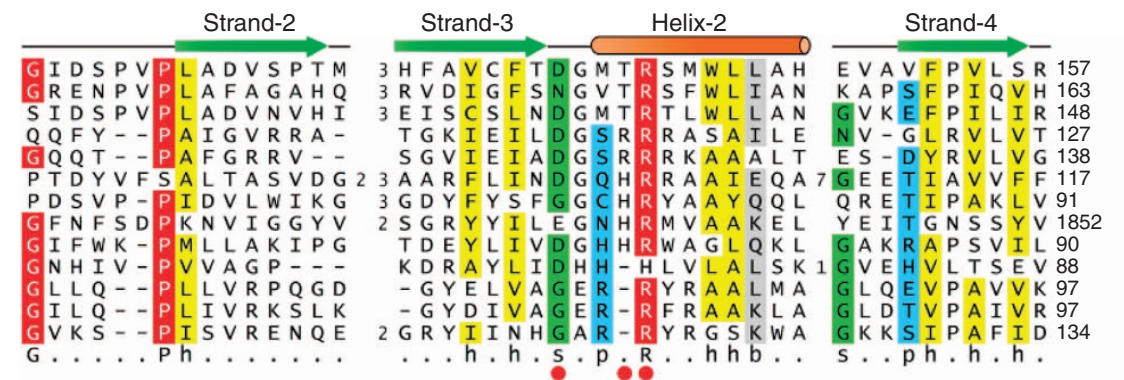

OSA
homologues
PhageP1
ParB-like
DndB
Sulfiredoxin
Toxin-ParB
Spo0J-like
RK2-KorB

Figure 1 | Crystal structure of Osa with predicted active site residues. (a) Cartoon representation of Osa (left) showing the position of conserved residues (right). Helices and strands corresponding to the conserved structural core of the ParB/Sulfiredoxin fold are in red and cyan respectively. Additional lineage-specific structural elements are coloured golden yellow. (b) Conserved structural core of the ParB/Sulfiredoxin fold: Osa (64-158), human Sulfiredoxin (hSrx:12-91, PDB:2rii) and ParB (Spo0J) from P. furiosus (Pfu ParB:16-90, PDB:1vk1). (c) Multiple sequence alignment of the ParB/Srx superfamily. Predicted active site residues are shown as red circles. Sequences are labelled by their gene and species names. The alignment is coloured based on 75\% consensus using the following scheme; p: polar residues (CDEHKNQRST) shaded blue, h: hydrophobic (ACFILMVWY) residues shaded yellow, s: small (ACDGNPSTV) residues shaded green and big (QRKEILMWYF) residues shaded grey. Absolutely conserved residues are shaded red. Secondary structure is shown above the alignment with the core ParB/Srx strands in green and helices in orange. The blue helix is only conserved in Osa homologues. (d) Electrostatic surface representation of the predicted active site of Osa is shown with putative active site residues marked. 


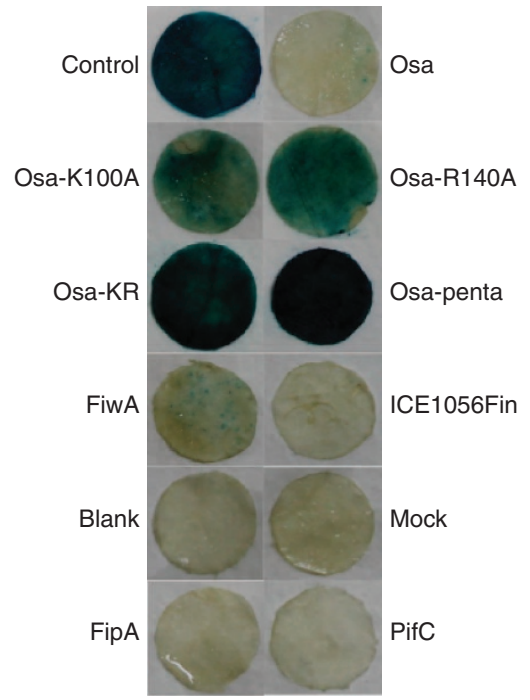

Figure 2 | Active site of Osa is essential for T-DNA transfer in vivo. Results of GUS ( $\beta$-glucuronidase) assay after agroinfiltration of Nicotiana tabaccum leaf discs are shown. Blue-green colour indicates GUS expression, and thus transfer of gus gene flanked with T-DNA borders from Agrobacterium into plant. Blank: Agrobacterium resuspension buffer, Mock: Agrobacterium tumefaciens LBA4404 strain alone, Control: LBA4404 containing pCAMBIA1301 and pSoup vector alone, without any insert. Test experiments had Agrobacterium clones harbouring pCAMBIA1301 and pSoup containing either Osa or one of its mutants, or other FINsICE1056Fin, FipA and PifC.

bioassay $^{21}$ showed that the single mutations (K100A; R140A) partially blocked T-DNA transfer through VirB/D4 T4SS (Fig. 2). However, Osa-KR and Osa-penta mutants failed to block T-DNA transfer into Nicotiana cells indicating complete loss of biological activity. As expected, native Osa completely blocked T-DNA transfer.

We also tested and found that Osa homologues including FiwA from RP1 and FIN p1056.10c (ICE1056Fin) encoded by an integrative and conjugative element of Haemophilus influenzae (ICEHin1056) (ref. 22) similarly blocked T-DNA transfer (Fig. 2). Thus our in planta experiments demonstrated that Osa and its two homologues require their cognate ParB/Srx-type active sites to block T-DNA transfer.

Osa exhibits ATPase and DNase activities. To understand how the predicted active site of Osa might relate to its biological function, we investigated its biochemical activities in vitro. Accordingly, we tested if ParB/Srx fold-mediated biochemical functions are conserved among Osa and other FINs. Pyrococcus furiosus ParB, a member of the superfamily possesses DNase activity $^{23}$, while another member, Arabidopsis thaliana Srx, possesses DNase activity and sulfinic acid-reducing activity, which requires ATP-dependent phosphotransfer ${ }^{24}$. Structural superpositions showed that key residues in the inferred active site pocket of human Srx (hSrx: K61, G97, R101) are conserved in Osa (K100, G137, R140) (Supplementary Fig. 2a) and located in the above-identified active site. We hence tested if this catalytic site might support ATPase activity, by using Osa and its mutants and a thin layer chromatography (TLC)-based assay to monitor $\gamma$ phosphate release. Native Osa readily hydrolysed ATP, and the predicted active site mutations abolished the ATPase activity (Fig. 3a). Likewise, Osa homologues ICE1056Fin, P1 ParB and RK2 KorB also exhibited comparable ATPase activity (Fig. 3a). Osa hydrolysed ATP and exhibited no comparable GTPase activity.
We next investigated if Osa possesses DNase activity. Assays with both ssDNA and dsDNA substrates showed that native Osa possesses sequence-nonspecific DNase activity, whereas the penta and single mutants were completely inactive (Fig. 3b,c). Similarly, ICE1056Fin, RK2 KorB and P1 ParB exhibited DNase activity (Fig. 3c; Supplementary Fig. 2b). The dual ATPase and DNase activities of Osa required $\mathrm{Mg}^{2+}$ and EDTA treatment abolished both activities (Supplementary Fig. 2c,d). Together, our findings establish that Osa and its homologues possess both ATPase and DNase activities and, furthermore, that the active site of Osa is required for both catalytic activities.

ATP-dependent regulatory switch in Osa. We found that the $\gamma-\mathrm{P}^{32} \mathrm{O}_{4}$ of $\left[\gamma-\mathrm{P}^{32}\right] \mathrm{ATP}$ bound to Osa, but not to its mutants (Fig. 3d). Interestingly, crystal structures of three members of ParB/Srx fold, Osa, Pfu ParB and hSrx have a bound phosphate in their conserved active site pockets (Supplementary Fig. 2e). The backbone nitrogens and side chains of T139, R140 in Osa form direct polar interactions with the bound phosphate, whereas the backbone nitrogens of G137, M138 and side chain nitrogen of K100 interact with it via water molecules. Mutation of a phosphate-binding residue from this pocket in hSrx $(\mathrm{H} 100 \mathrm{~N})$ resulted in complete loss of activity ${ }^{25,26}$. Examination of bound phosphates in these proteins, along with data from our current study, suggests that the $\gamma$-phosphate released on hydrolysis can occupy the position occupied by the $\beta$-phosphate when ATP is bound to the active site. Given that the $\gamma$-phosphate is retained in the active site on ATP hydrolysis across distant members of the ParB/Srx fold, we postulated that phosphate binding plays an important biochemical function.

As the ATPase and DNase activities depend on the same active site residues in Osa, we reasoned that availability of ATP could affect its DNase activity, with the retained phosphate potentially blocking DNA binding. To test this, we incubated Osa with its ssDNA substrate with and without ATP in the reaction mixture. While in the absence of ATP Osa showed notable DNase activity, presence of ATP inhibited its DNase activity towards the same substrate (Fig. 3e). Similar ATP-dependent inhibition was observed for the DNase activity of ICE1056Fin and RK2 KorB (Fig. 3e). On the contrary, presence of plasmid DNA did not affect the ATPase activity of Osa (Supplementary Fig. 2f). We also found magnesium to be more conducive for DNase activity than calcium (Fig. 3f). These findings suggest that ATP acts as a negative regulatory switch for metal-ion-dependent DNase activity across diverse members of the ParB/Srx superfamily.

Osa undergoes multimerization. Though Osa was crystallized with one molecule per asymmetric unit, we found it to be in equilibrium with multimeric states in solution even in the absence of substrate DNA (Supplementary Fig. 3a,b). When Osa and ICE1056Fin were incubated at $4{ }^{\circ} \mathrm{C}$ with either covalently closed circular or linearized dsDNA or ssDNA, they formed nucleoprotein complexes (Supplementary Fig. 3c). Increasing concentrations of Osa and ICE1056Fin resulted in increased supershifting of DNA, suggesting that Osa and its homologue ICE1056Fin form higher-order oligomers on binding DNA. It is also apparent from the existing data that ParB and Sulfiredoxin also undergo oligomerization. ParB forms a high-order nucleoprotein complex as it binds repetitive parS sites during pairing of plasmids before partitioning ${ }^{27-29}$. Similarly, Arabidopsis Srx too causes a DNA-mobility shift ${ }^{24}$. These observations suggest that oligomerization upon DNA binding might be a widespread characteristic of members of the ParB/Srx fold. 
a

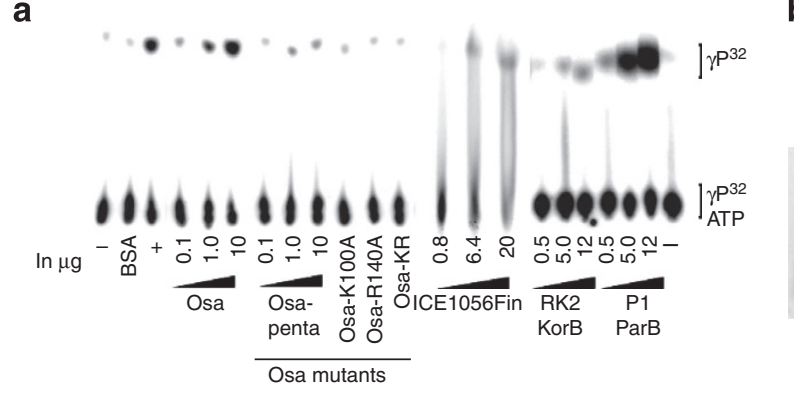

b

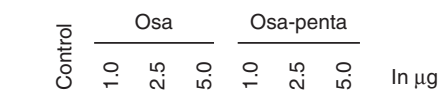

C
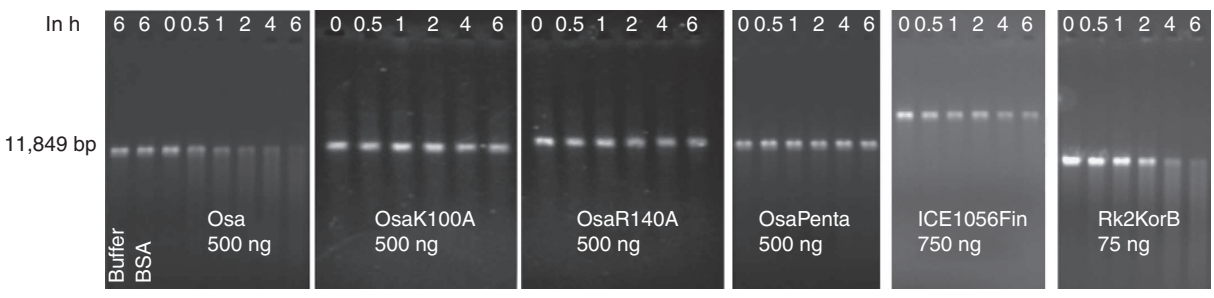

d

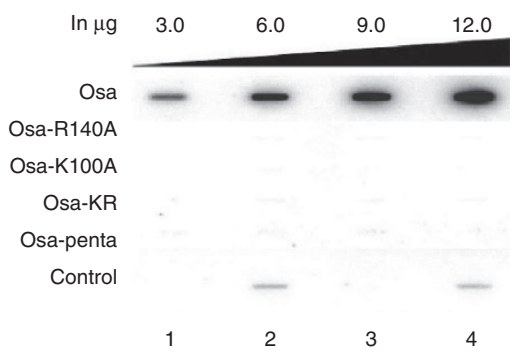

e

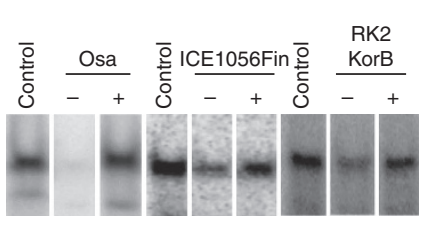

f

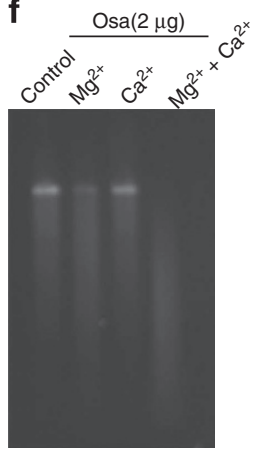

Figure 3 | The active site of Osa catalyzes both DNase and ATPase activities, and is controlled by an ATP-dependent regulatory switch.

(a) ATPase activity: TLC plates were loaded with samples after ATP hydrolysis. Rv3868 of $M$. tb, a known ATPase, was used as a positive control. (b) DNase activity: A 90-meric ssDNA was used as a substrate. (c) DNase activity of Osa mutants and various ParB/Srx superfamily proteins using linearized pCAMBIA1301 as the substrate. (d) $\gamma$-phosphate retention after ATP hydrolysis: slot blot overlayed with $\left[\gamma\right.$-P $\left.{ }^{32}\right]$ ATP. The control lanes were loaded with 1: BSA, 2,4: Cdk2/Cyclin E kinase (Abcam). Slots overlayed with $\left[\alpha-\mathrm{P}^{32}\right]$ ATP did not show comparable bound radioactivity, confirming bound $\gamma$-Phosphate. (e) The ATP-dependent switch in Osa, ICE1056Fin and RK2 KorB: nuclease reactions were performed using labelled 90-mer ssDNA substrate with $5-10 \mu \mathrm{g}$ of proteins for $6 \mathrm{~h}$ at $37^{\circ} \mathrm{C}$ and loaded onto $4-16 \%$ TBE-PAGE. ' - ' and ' $+{ }^{\prime}$ ' indicate the absence and presence of $10 \mathrm{mM}$ ATP in the reaction mix. (f) Metal-ion dependency of Osa DNase activity. Osa shows optimal DNase activity in the presence of magnesium ion than calcium.

Osa cleaves T-DNA at the VirB/D4 T4SS machine. Having characterized its biochemical activities, we tried to place these activities in the larger context of Osa function. Earlier studies showed that Osa fractionates with the membrane ${ }^{30}$ and colocalizes in vivo with VirD4, the coupling protein of the $A$. tumefaciens VirB/VirD4 T4SS ${ }^{16}$. To investigate possible interactions of Osa with relaxosome and/or VirB/D4 T4SS components, we expressed FLAG-Osa in WT A. tumefaciens strain A348 (ref. 31), and co-immunoprecipitated its interacting partners using anti-FLAG antibodies. In addition to immunoprecipitating Osa, FLAG-specific antibodies pulled down VirB4 (Fig. 4a) and VirB11 (Fig. 4b). Such an interaction was neither dependent on the VirD4 coupling protein nor on the assembly of the T4SS machine (Fig. 4a,b). Reciprocally, antibodies to VirB4 and VirB11 specifically pulled down FLAG-Osa. To evaluate the in vitro interactions of Osa with T4SS machine and relaxosome components, we first cloned, overexpressed and purified from E. coli soluble forms of the three T4SS ATPases viz VirB4 (425-743 aa), VirB11 (full length) and VirD4 (87-543 aa), and two of the relaxosome components viz $\operatorname{VirC1}$ and VirC2.
Next, we tested and confirmed, using TLC assays, that our purified VirB4, VirB11, VirC1 and VirD4 exhibit significant ATPase activities (Supplementary Fig. 4). Again, far-western analyses showed Osa to interact with VirB4 (425-743 aa) and VirB11 (Fig. 4c). These results are in clear agreement with the observed in vivo interactions (Fig. 4a,b). However, in these conditions, Osa did not interact with VirC1, VirC2 and VirD4. Interestingly, we observed a similar pattern of interaction with ICE1056Fin (Fig. 4c). Interaction of both Osa and ICE1056Fin with their cognate T4SS machine components, VirB4 and VirB11 supports a role for this association in plasmid fertility inhibition.

To explore the action of Osa in a complex with the T4SS components, we reconstituted the fertility inhibition complex in vitro, using a partial T4SS complex consisting of VirB4 (425743 aa), VirB11 (full length) and Osa or Osa-penta mutant. In the presence of reconstituted partial T4SS machine, Osa degraded T-DNA covalently linked to VirD2 (ref. 32), whereas the penta mutant failed to do so (Fig. $5 \mathrm{a}-\mathrm{c}$ ). These data suggest that Osa degrades VirD2-linked T-DNA (Fig. 5d) even in presence of the T4SS in vitro despite being protected from other nucleases ${ }^{33}$. 


\section{Discussion}

Our findings help elucidate the molecular mechanism of Osa and its homologues in blocking co-resident rival plasmid transmission and A. tumefaciens oncogenicity. Osa degrades T-DNA both when it is crosslinked to the tyrosine of the RCR superfamily relaxase VirD2 (Fig. 5b) and when VirD2-bound T-DNA associates with the T4SS inner-membrane complex components in vitro (Fig. 5c). These observations together with previous studies suggest that Osa probably acts before T-DNA docking at VirD4 and that it may not target T-DNA until it reaches the T4SS machine $e^{34,35}$. Overall, our in vitro FIN reconstitution experiments support a model wherein the FINs first localize to the membrane and interact with T4SS machine components encoded by their rival plasmids before degrading the translocating DNA linked to their relaxases (Fig. 5d). Interestingly, Osa has also been shown to block the transfer of virulence effector proteins secreted by the $\mathrm{Ti}$ plasmid-encoded T4SS, namely VirE2 and $\mathrm{VirF}^{18,36}$. Physical association of Osa with the above T4SS components could also play a key role in blocking other macromolecular translocations via this system.

This also presents a conundrum as to how FIN factors specifically target 'non-self T4SS encoded by the co-resident plasmids as opposed to 'self versions encoded by their own DNA. Indeed a network of non-self plasmid-blocking interactions has
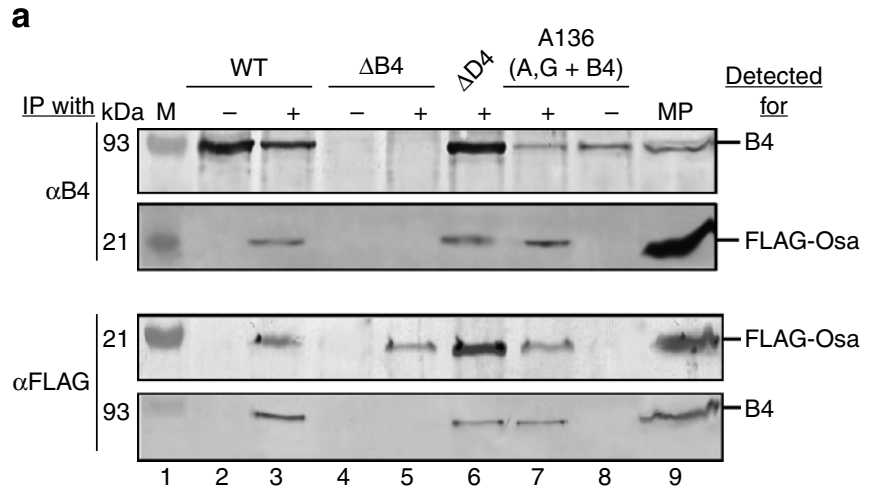

b
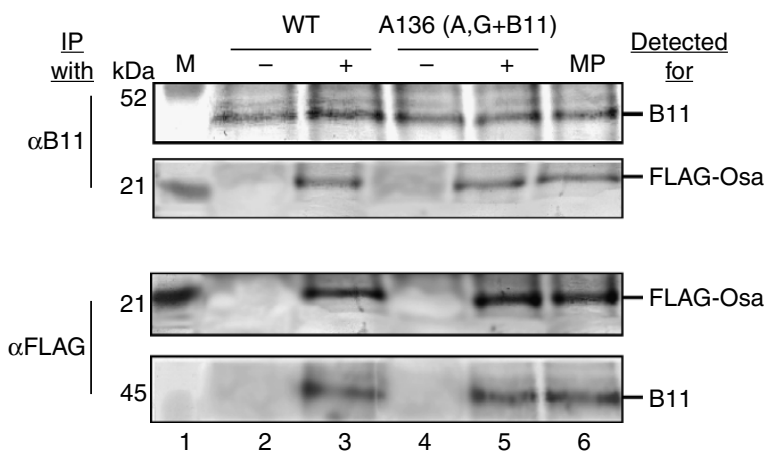

c

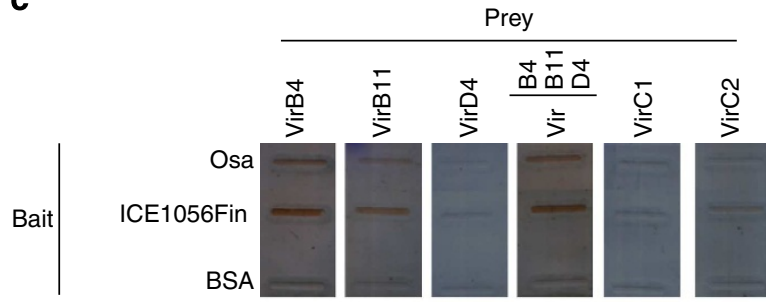

MBP been observed for other FINs: FiwA of RP1 (IncP $\alpha)$ blocks pSa (IncW) and FipA of pKM101 (IncN) and PifC of F (IncF) block RP1 (IncP) transfer ${ }^{11,13,37}$. Our data suggest that FINs might interact specifically with non-self T4SS components. To investigate if other co-factors might be involved in assisting Osa and related FINs in self versus non-self T4SS recognition, we conducted a computational analysis of their genomic contexts to identify conserved gene neighbourhoods or predicted operons. The presence of such conserved operons is a good indicator of interactions between the encoded proteins ${ }^{38,39}$. This analysis revealed that Osa and its homologues tend to be encoded in the vicinity of operons encoding transfer-associated or replicationassociated genes. These genomic neighbourhoods also include other loci involved in distinct biological conflict systems, such as toxins (Supplementary Fig. 5a). We observed that a common denominator in these genomic neighbourhoods is a gene coding for a predicted $\beta$-barrel domain typified by the $\mathrm{KfrB}$ protein from RK2 plasmid ${ }^{40}$ (Supplementary Fig. 5b). This domain is either encoded by a gene neighbouring Osa and its homologues (labelled Nuc in the pSa plasmid) or is fused to diverse toxin domains such as DOC (a protein nucleotidyltransferase) ${ }^{41}$, Zetatoxin (a kinase acting on substrates such as peptidoglycan) ${ }^{42}$ and HEPN (a predicted RNase) ${ }^{43,44}$. Given these associations (Supplementary Fig. 5a), it is conceivable that the KfrB domain plays a key role in discrimination of self from non-self and plays an auxiliary role in aiding Osa to target non-self T4SS.

All FINs tested in this study, both those related to Osa, such as FiwA, and ICE1056Fin and unrelated ones namely FipA and PifC blocked T-DNA transfer in vivo (Fig. 2). While Osa and its homologues FiwA and ICE1056Fin are expected to exhibit a similar mechanism, FipA and PifC belong to completely unrelated superfamilies of proteins and probably have their

Figure 4 | Interaction of Osa with VirB/D4 T4SS machine components in vivo and in vitro. For in vivo study: $\mathrm{N}, \mathrm{N}$-Dimethyldodecylamine $\mathrm{N}$-oxide (DDAO)-solubilized membrane protein material immunoprecipitated with (IP with) antibodies to VirB4 ATPase (a) or VirB11 ATPase (b) proteins and FLAG-tag $(\mathbf{a}, \mathbf{b})$ listed on the left were analysed for (detected for) proteins listed on the right. Total DDAO-solubilized membrane preparation (MP, right) from the WT (A348) or WT-expressing FLAG-Osa show the position of VirB4/VirB11 and FLAG-Osa, respectively. Absence or presence of FLAGOsa-expressing plasmid (pKA197) in all strains is indicated by-and + , respectively. Molecular weight markers ( $M$; lane 1$)$ and their sizes in $\mathrm{kDa}$ are shown in left. (a) Osa interacts with VirB4 independently of T4S machine and VirD4: Co-immunoprecipitation of VirB4 ATPase and FLAGOsa in the absence of VirD4 coupling protein and T4S machine. Strains: WT with (lane 3) and without (lane 2) expressing FLAG-Osa (pKA197); $\triangle B 4$ (PC1004 (virB4 knockout (KO)) with (lane 5) and without (lane 4) expressing FLAG-Osa (pKA197); $\triangle D 4$ (M×355 (virD4 KO) expressing (lane 6) FLAG-Osa (pKA197); A136 (A, G + B4) (KA2002 (WT deleted of pTiA6 plasmid and supplemented with VirA sensory kinase and VirG response regulator) expressing VirB4 (pKA93) with (lane 7) and without (lane 8) producing FLAG-Osa (pKA197). (b) Osa interacts with VirB11 independently of T4S machine and VirD4: co-immunoprecipitation of VirB11 ATPase and FLAG-Osa in the absence of T4S machine. Strains: WT with (lane 3) and without (lane 2) expressing FLAG-Osa (pKA197); A136 (A, $\mathrm{G}+\mathrm{B} 11$ ) (KA2002 (WT deleted of pTiA6 plasmid and supplemented with VirA sensory kinase and $\operatorname{VirG}$ response regulator)) expressing VirB11 (pSR40) with (lane 5) and without (lane 4) producing FLAG-Osa (pKA197). For in vitro study: (c) Far-western blot of purified MBP fused VirB/D4 T4SS and relaxosome components with purified Osa and ICE1056Fin, probed using horseradish peroxidase-conjugated anti-MBP antibody. Osa and two other FIN factors were used as baits to trap the interacting partner from the T4SS machine and relaxosome. 
a

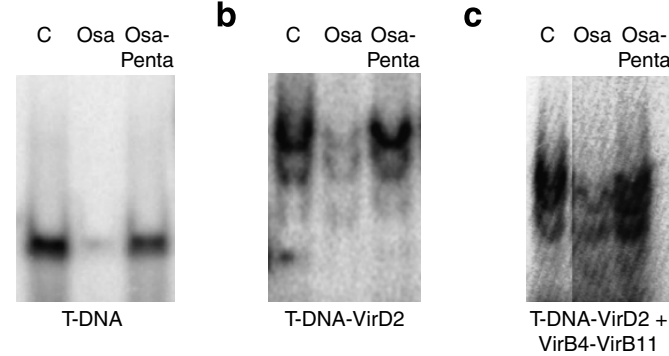

d
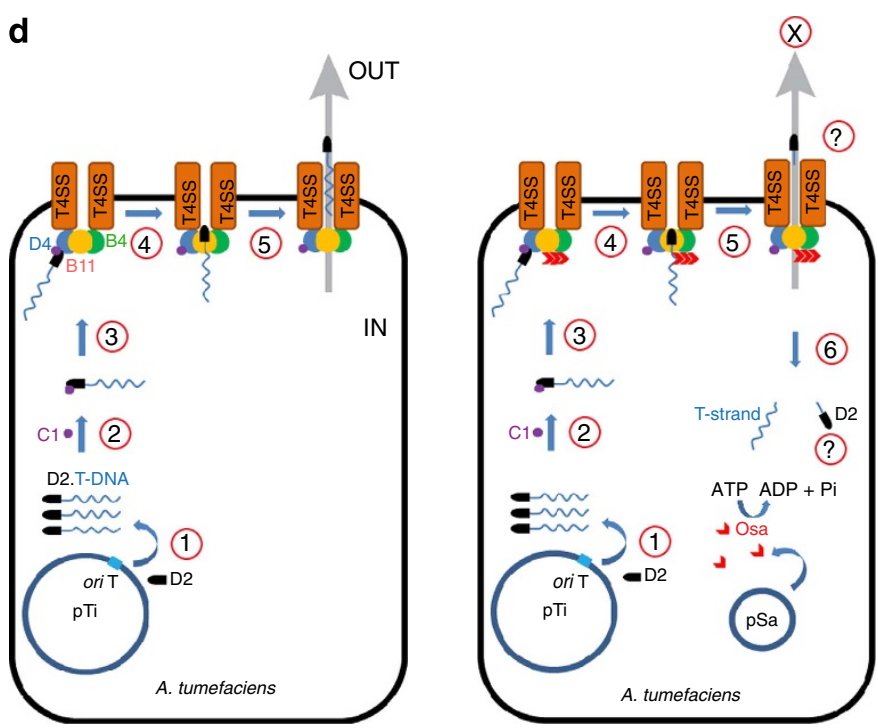

Figure 5 | In vitro reconstitution of plasmid fertility inhibition and the FIN model. Osa digests naked T-DNA (a), T-DNA linked to VirD2 in the absence (b) and presence of T4SS ATPases VirB4 and VirB11 (c). (d) Proposed model of plasmid fertility inhibition by Osa-like FIN factors. The model on the left illustrates T-DNA transfer during normal conjugation/ agroinfection process. In an assumed series of steps, first VirD2 relaxase makes a nick at the $5^{\prime}$ end of right border (RB) sequence, and gets covalently linked to the single-stranded T-DNA (step 1). The T-complex containing T-DNA.VirD2-VirC1 (step 2) docks to the coupling factor VirD4 at the T4SS, through the physical interaction between VirC1 and VirD4 (step 3). Then, the T-DNA docked at the cytoplasmic side of T4SS is channelled through the pore (step 4 and 5 ). Thereby, the T-DNA substrate is either released in the vicinity or secreted into the cytoplasm of the recipient bacterial host or the plant cell. The model on the right side depicts the possible fate of T-DNA in the presence of an Osa-like FIN factor encoded from a co-resident plasmid pSa. Osa, which is already localized in the vicinity of the membrane, binds to preassembled T4SS through its interaction with VirB11 and VirB4. At this stage, Osa blocks T-DNA transfer through T4SS by two ways (step 4 and step 5): (i) Osa decouples T-DNA from VirD2 through its DNase activity, and (ii) also modulates VirB4-B11D4 interaction, wherein VirD4 coupling factor loses its affinity to the substrates (step 6). Without VirD2, and also no longer being recognized by VirD4, the decoupled T-DNA cannot hitchhike its way to the other side of the cell. For the sake of clarity, only limited components of T4SS are shown.

own distinct mechanisms. Moreover, plasmids of the IncP $\alpha$ group also deploy as FINs products of the Ter locus (FiwB) ${ }^{11}$, which has also been implicated as a defensive mechanism against bacteriophages $^{45}$ and toxic substances such as Tellurium. The products of the Ter locus are predicted to form membraneassociated complexes that might interfere with fertility of rival plasmids ${ }^{45}$. Thus, we expect a rich diversity of mechanisms to convergently target the T4SS or the DNA substrate as part of the fertility inhibition phenomenon.
Our study shows that ATPase and DNase activities are common features across the ParB/Srx superfamily, with retention of the $\gamma$-phosphate at the active site and inhibition of DNase activity in presence of ATP. This observation suggests that the DNase activity of Osa-like FINs is likely to be kept in check under normal conditions by the ambient presence of ATP. However, when it associates with the T4SS, the active P-loop ATPases in that complex likely consume ATP creating a local depletion. This in turn might allow unmasking of their DNase activity towards rival T-DNA undergoing transfer.

Presence of comparable dual activity across members of the ParB/Srx fold suggests that this might have more general implications for their functions. Members of ParB/Srx superfamily are found in biologically diverse contexts: (1) Cellular genomic-, viral- and plasmid-encoded ParBs are involved in partitioning of their corresponding DNA; (2) Sulfiredoxins restore the activity of oxidized peroxiredoxin in an ATPdependent manner; they transfer the $\gamma$-phosphate to cysteine sulfinic acid in the peroxiredoxin active site with its resultant conversion to a $\mathrm{SH}$ group $^{46}$; (3) Certain recently identified members of the polymorphic toxin systems contain carboxylterminal (C-terminal) ParB toxin domains that are predicted to function as nucleases ${ }^{47}$; (4) DndB and related proteins are involved in regulating DNA phosphorothioation and other recently proposed DNA modifications ${ }^{48,49}$; (5) Certain bacteriophage and related ParB/Srx superfamily proteins are associated with facilitating DNA modifications ${ }^{48}$.

Of these, the proteins involved in chromosomal segregation across bacteria (for example, Bacillus subtilis Spo0J, Caulobacter ParB and bacteriophage P1 ParB point to two unifying themes: First, they stimulate the activity of a ParA-like ATPase; second, they possess a C-terminal DNA-binding helix-turn-helix domain with which they can recognize specific sequences at the origins of replicons (ParS sequences). However, current studies on chromosome partitioning ${ }^{50-52}$ do not take into account either the DNase or the ATPase activities of ParB. Since we were able to detect both these activities in phage P1 ParB and RK2 KorB, we propose that they are essential for chromosome partitioning. As with Osa, we propose that the DNase and DNA-associating activity of the ParB/ Srx domain of these proteins (as opposed to the helix-turn-helix domain) is kept under check by ATP. However, when ATP is locally depleted by ParA(Soj)'s ATPase activity, the DNase and DNAassociation activity of the ParB/Srx domain is unleashed, perhaps allowing it to associate with the nucleoid DNA and locally cut it. This in turn might affect its interaction with DNA and explain the observed dynamical reassociation with DNA during segregation. Consistent with this, mutation of a conserved arginine (R80A) in Spo0J, which corresponds to an active site residue in Osa (R140), results in loss of function ${ }^{53}$ (Fig. 1c). Similarly, the dual activities of other members of the family could also regulate their DNase and DNA-association properties to control DNA modification (for example, DndB) or toxin activity of the polymorphic toxins.

In summary, we report the crystal structure of plasmidencoded FIN Osa. The core of Osa adopts the ParB/Srx fold with a unique active site displaying both ATPase and DNase activity, the latter being negatively regulated by an ATP-dependent switch. Osa degrades Ti plasmid-encoded T-DNA in the T-DNA:VirD2 complex before its translocation through VirB/D4 T4SS machine, a mechanism conserved in Osa-like FINs. Our results offer a unified mechanism that generates testable hypotheses for the roles of a hitherto obscure superfamily of proteins implicated in a wide range of biological functions.

\section{Methods}

Cloning, overexpression and mutagenesis. Native Osa, Osa mutants-Osa-KR (K100A-R140A), Osa-penta (D98A-K100A-D136A-T139A-R140A) - and genes 
encoding FIN factors FiwA, p1056.10c (ICE1056Fin), FipA and PifC, were PCR amplified and cloned into pKA165 (containing pvirB::osa) ${ }^{16}$ by replacing osa (Supplementary Table 1). HindIII and KpnI cut, error-free inserts were then mobilized into pSoup for agroinfiltration, and to pETM-41 (EMBL-vector collection) or pET-28a for overexpression in E. coli. PCR cloning and site-directed mutagenesis, using pKA165 as template, was carried out with primers listed in Supplementary Table 2. Agrobacterium tumefaciens (A. tumefaciens) octopinespecific pTiA6-encoded virB4, virB11, virD4, virCl and virC2 were cloned into InfR-Nhis, and then mobilized into pETM-41 for overexpression. virD2, P1 parB and RK2 korB were PCR amplified from pTiA6, phage P1 lysate and RP4 plasmid DNA, respectively, and cloned into InfR-Nhis for overexpression. FLAG-Osa was PCR amplified with specific primers (Supplementary Table 2) using pUCD3960 (ref. 18) as template. The 0.6-kb amplicon was subsequently cloned into the corresponding sites of pPC914KS + (ref. 54) to obtain pKA197 and finally ligated to the broad host range plasmid pSW172 $\left(\mathrm{Tet}^{\mathrm{R}}\right)^{55}$. Escherichia coli DH5 $\alpha$ was used as the host strain for all plasmid constructions. InfR-Nhis is an in-house modified pRSF-Duet1 vector (Novagen) with In-Fusion (Clonetech) cloning cassette containing TEV protease cleavable $\mathrm{N}$-terminal $\mathrm{His}_{6}$-tag.

Purification and crystal structure determination of Osa. Osa with N-terminal $\mathrm{His}_{6}$-tag was purified using $\mathrm{Ni}^{2+}$ affinity and gel-filtration chromatography, and crystallized using hanging and sitting drop methods at a concentration of $6 \mathrm{mg} \mathrm{ml}^{-1}(0.284 \mathrm{mM})$. Best diffraction quality crystals of Osa were obtained in $8 \% 2$-propanol $(\mathrm{v} / \mathrm{v}), 0.5 \mathrm{M}$ Lithium sulfate, $0.1 \mathrm{M}$ Phosphate-citrate buffer ( $\mathrm{pH} 4.2$ ) and $0.2 \mathrm{M}$ Non-detergent sulphobetaine (NDSB-201). X-ray data sets for native and $\mathrm{KAu}(\mathrm{CN})_{2}$-soaked Osa crystals were collected at $100 \mathrm{~K}$ using home source fitted with Mardtb image plate (mar345) and a RigakuMicromax 007 rotating anode generator $\left(\mathrm{Cu} \mathrm{K}_{\alpha} \lambda=1.5418 \AA\right)$ operated at $40 \mathrm{kV}$ and $20 \mathrm{~mA}$ or R-AXIS IV ${ }^{+}+$image plate and FR-E SuperBright rotating anode generator at the National Institute of Immunology, New Delhi. Paratone oil (Hampton Research) and glycerol were used as cryo-protectants. Data were processed using HKL-2000 (ref. 56). Phases were calculated using single isomorphous replacement with anomalous scattering method in HKL2MAP ${ }^{57}$. Model building was carried out using Buccaneer ${ }^{58,59}$ and $\operatorname{Coot}^{60}$. Phenix ${ }^{61}$ was used for refinement. Ramachandran statistics were checked using PROCHECK ${ }^{62}$. Structural comparison was done using DALI ${ }^{19}$. Figures were made using Chimera ${ }^{63}$ and PyMol (Schrödinger, LLC).

Multiple sequence alignment. Sequence profile searches using the PSI-BLAST ${ }^{64}$ programme and the HMMsearch programme of the HMMER3 package ${ }^{65}$ were used to identify diverse ParB/Srx homologues. The multiple sequence alignment was generated using Kalign2 (ref. 66) followed by manual adjustments based on structural alignments generated by the DALI server.

Overexpression and purification of all other proteins. Overexpression screening was carried out using various $E$. coli host strains with appropriate antibiotics in prescribed concentrations, and the ones that yielded optimal amount of target proteins are listed in Supplementary Table 1. Brief expression and purification protocols for individual proteins are given below. Compositions of the buffer used are in the Supplementary Table 3. All the prepacked chromatographic columns used in this study are from GE biosciences. Ultracentrifugation devices (Millipore) with various molecular weight cutoff were used for protein concentrations.

MBP-Osa and its mutants. These proteins were expressed in Rosetta2 (DE3) pLysS strain (Novagen) and purified in four steps, first by amylose affinity, followed by $\mathrm{Ni}^{2+}$-affinity, Ion-exchange (HiTrap-Q-HP) and gel-filtration chromatographic columns. Cells grown at $37^{\circ} \mathrm{C}$ in Luria-Bertani (LB) broth were induced with isopropyl- $\beta$-D-thiogalactoside (IPTG) at $\mathrm{OD}_{600} 0.8$ and incubated further for $4 \mathrm{~h}$. Cells were sonicated and the clarified lysate supernatant in buffer C, containing $500 \mathrm{mM} \mathrm{NaCl}$, was passed through amylose resin (NEB), equilibrated with the same buffer and eluted with $20 \mathrm{mM}$ D-Maltose. Eluted protein was loaded onto HisTrapFF column charged with Nickel sulphate, washed with buffer A and eluted with buffer B. Salt concentration in the eluted fraction was diluted to $10 \mathrm{mM} \mathrm{NaCl}$, and was loaded onto $5 \mathrm{ml}$ Hitrap-Q-HP column and eluted using a 10-1,000 mM $\mathrm{NaCl}$ gradient. Pooled and concentrated fractions were further purified using Hiload 16/60 Superdex S-200 column.

ICE1056Fin. C-terminal $\mathrm{His}_{6}$-tagged protein was expressed in E. coli BL21CodonPlus cells in LB autoinduction (LB-AI) without trace elements and TB autoinduction media with trace elements (Formedium, UK), respectively. Both secondary cultures were grown at $25^{\circ} \mathrm{C}$ for $24 \mathrm{~h}$. Cells were lysed in lysis buffer 1 , and the lysate supernatant was loaded onto HisTrapFF $\mathrm{Ni}^{2+}$ affinity column. The column was washed first with buffer A followed by the same buffer containing $50 \mathrm{mM}$ imidazole and eluted with $250 \mathrm{mM}$ Imidazole. Fractions containing pure target proteins were pooled, concentrated and loaded onto Hiload Superdex S-200 $16 / 60$ column preequilibrated with buffer D.
VirB11 and VirD4. The overexpression constructs were transformed into E. coli Rosetta2 (DE3) pLysS cells. Cells were grown in LB-AI medium without trace elements at $25^{\circ} \mathrm{C}$ for $24 \mathrm{~h}$ and lysed in lysis buffer 1 , and the lysate supernatant was then gently mixed with amylose resin in batch mode, before packing onto a manual gravity-flow column. Three times the bed volume of buffer E containing $0.05 \%$ Triton-X-100 was used to wash off non-specifically bound proteins. Buffer E containing $0.5 \mathrm{mM}$ D-Maltose was used for further washing and then eluted with buffer F. Proteins were further purified using Superdex S-200 16/60 column equilibrated with buffer $\mathrm{G}$.

VirB4. VirD4 was expressed in E. coli $\mathrm{T} 7$ Express $l y s Y / I^{q}$ (NEB) cells in LB broth. Cells grown at $37^{\circ} \mathrm{C}$ till $\mathrm{OD}_{600} 0.6$ and then induced with $0.5 \mathrm{mM}$ IPTG at $25^{\circ} \mathrm{C}$ for $12 \mathrm{~h}$. Cells lysed in lysis buffer 2 were batch bound to amylose resin, washed with buffer $\mathrm{H}$ and eluted with $10 \mathrm{mM}$ maltose. It was then dialyzed against $20 \mathrm{mM}$ Tris- $\mathrm{HCl} \mathrm{pH} 7.4$ and $50 \mathrm{mM} \mathrm{NaCl}$.

VirC1 and VirC2. These proteins were expressed in E. coli T7 Express $I^{q}$ (NEB) cells using $\mathrm{LB}$ broth. Cells grown at $37^{\circ} \mathrm{C}$ till $\mathrm{OD}_{600} 0.6$ were induced with $0.5 \mathrm{mM}$ IPTG and further grown for $5 \mathrm{~h}$. Cells were lysed in lysis buffer 1, and the lysate supernatant was batch bound to amylose resin, washed with buffer $\mathrm{E}$ and eluted using buffer F. VirC2 was purified to homogeneity by amylose affinity chromatography, whereas VirC1 needed further purification using HisTrapFF affinity column. Column was washed with buffer A followed by wash with buffer A containing $50 \mathrm{mM}$ imidazole and eluted with $100 \%$ buffer B.

VirD2. VirD2 was expressed in E. coli BL21-CodonPlus(DE3) cells in LB broth. Cells grown at $37^{\circ} \mathrm{C}$ till $\mathrm{OD}_{600} 1.0$ were induced with $0.5 \mathrm{mM}$ of IPTG and grown further for $12 \mathrm{~h}$ at $25^{\circ} \mathrm{C}$. Overexpressed full-length VirD2 was found in the inclusion bodies and a standard protocol was followed for refolding and purification ${ }^{67}$.

ParBs. RK2 KorB was expressed in E. coli Rosetta 2(DE3) pLysS cells in LB broth. Cells were grown at $37^{\circ} \mathrm{C}$ until $\mathrm{OD}_{600} 1.0$ and then induced with $0.5 \mathrm{mM}$ IPTG at $25^{\circ} \mathrm{C}$ for $12 \mathrm{~h}$. Cells were lysed in lysis buffer 1 and the lysate supernatant was passed through $5 \mathrm{ml}$ HisTrapFF column. The column was washed with buffer A and eluted with $75 \mathrm{mM}$ Imidazole. Pure fractions of KorB were pooled and dialyzed into buffer I before passing onto HiTrap-Heparin HP column. Protein was eluted using a gradient run using buffer I and J. KorB eluted around $\sim 140 \mathrm{mM} \mathrm{NaCl}$. P1 ParB was expressed in T7 Express lys $Y / I^{q}$ in LB broth. Cells were grown at $37^{\circ} \mathrm{C}$ until $\mathrm{OD}_{600} 0.6$ and then induced with $0.5 \mathrm{mM}$ IPTG for $2 \mathrm{~h}$. Cell lysate supernatant in lysis buffer 2 was passed through $10 \mathrm{ml}$ of chelating sepharose column charged with $\mathrm{Co}^{2+}$. Column was washed with buffer $\mathrm{K}$ and eluted with a gradient using buffer $\mathrm{K}$ and $\mathrm{L}$. Pure fractions were pooled and dialyzed against buffer $\mathrm{M}$ to remove excess salt and loaded onto a cation-exchange column ( $5 \mathrm{ml}$ HiTrap-SPSepharose) and eluted using buffer $\mathrm{N}$ containing 50 to $1,000 \mathrm{mM} \mathrm{NaCl}$ gradient. The N-terminal His-tag was cleaved with TEV protease (20:1 protein to protease ratio) at $20^{\circ} \mathrm{C}$ for $16 \mathrm{~h}$. Cleaved His6-tag and the uncut fusion proteins were removed by passing through a 5-ml HisTrapFF column. Pure P1 ParB containing fractions were pooled and passed through GPC column (Superdex S-75 10/60) equilibrated with buffer M. P1 ParB purified to homogeneity was further passed through $5 \mathrm{ml}$ HiTrap-Heparin HP column in buffer I, followed by a gradient run using buffer I and J.

ATP binding and hydrolysis. Purified proteins were blotted onto nitrocellulose membrane using a multi-well slot-blot manifold, blocked with $5 \%$ bovine serum albumin (BSA) at $4{ }^{\circ} \mathrm{C}$ for $2 \mathrm{~h}$, washed thrice with PBS containing $0.05 \%$ Tween- 20 (PBS-T) followed by three washes with PBS (without Tween-20), for $5 \mathrm{~min}$ each. Twenty $\mu \mathrm{Ci}$ of $\gamma$ - $\mathrm{P}^{32}$ radio-labelled ATP in $15 \mathrm{ml}$ of PBS containing $10 \mathrm{mM} \mathrm{MgCl}_{2}$ was added to the blot and incubated for $30 \mathrm{~min}$. This was followed by three PBS-T washes and then three PBS washes, each for $5 \mathrm{~min}$. The blot was dried and exposed for $12 \mathrm{~h}$ and developed using phosphor imager (GE). Slots overlayed with [ $\alpha$ $\mathrm{P}^{32}$ ]ATP did not show comparable bound radioactivity, confirming bound $\gamma$ phosphate. For ATPase assay, proteins were incubated with $0.2 \mu \mathrm{Ci}\left[\gamma-\mathrm{P}^{32}\right] \mathrm{ATP}$ in the reaction buffer containing $10 \mathrm{mM}$ Tris- $\mathrm{HCl} \mathrm{pH} 8.0,5 \mathrm{mM} \mathrm{MgCl}_{2}, 50 \mathrm{mM} \mathrm{KCl}$, $2 \mathrm{mM}$ DTT and $80 \mu \mathrm{g} \mathrm{ml}^{-1}$ BSA. The reactions were carried out for $30 \mathrm{~min}$ at $37^{\circ} \mathrm{C}$ and then $1.1 \mu \mathrm{l}$ of the mixture was spotted on polyethyleneimine cellulose TLC plate (Sigma). TLC was run with mobile phase containing $0.5 \mathrm{M} \mathrm{LiCl}$ and $1 \mathrm{M}$ formic acid. After the run, TLC plate was air dried and developed using phosphor imager, $2 \mathrm{~h}$ after exposure.

DNase assay. The assays were performed in a $20-\mu \mathrm{l}$ reaction mixture containing $50 \mathrm{ng}$ linearized dsDNA substrate in nuclease buffer: $50 \mathrm{mM}$ Tris-HCl pH 8.0, $50 \mathrm{mM} \mathrm{NaCl}, 5 \mathrm{mM} \mathrm{MgCl}_{2}$ and $3 \mathrm{mM} \beta$-ME. The assay mixture was incubated at $37^{\circ} \mathrm{C}$ for $4 \mathrm{~h}$ and run on $1.0 \%$ agarose gel. For DNase assay with ssDNA substrate, a 90-mer oligo (Supplementary Table 2) was commercially synthesized and the 3 end was labelled with $\left[\alpha-\mathrm{P}^{32}\right] \mathrm{dCTP}$ using terminal transferase (NEB) following manufacturer's protocol. Aliquots corresponding to 30,000 counts of this labelled 
ssDNA were incubated with respective proteins for $6 \mathrm{~h}$ in the nuclease buffer, with and without different divalent cations and EDTA. Sample aliquots were mixed with protein loading buffer and run on a 4 to $16 \%$ gradient TBE-polyacrylamide gel electrophoresis (PAGE), after which the gels were exposed and scanned.

Agroinfiltration and GUS assay. Agrobacterium tumefaciens LBA4404 strain was co-transformed with pCAMBIA1301 and pSoup constructs containing osa, osa mutants, fiwA, ice1056fin, fipA and pifC, under virB promoter, by electroporation. Transformants were selected on YEM-Agar plates supplemented with 50, 50, 5 and $10 \mu \mathrm{g} \mathrm{ml}^{-1}$ of kanamycin, streptomycin, tetracycline and rifampicin, respectively. Single colonies were cultured in YEM (Yeast extract-Mannitol) medium supplemented with appropriate antibiotics at $28^{\circ} \mathrm{C}$ and at 180 r.p.m. until the cell density reached $\mathrm{OD}_{600}$ 1.0. Cells were harvested and resuspended in infiltration buffer containing $10 \mathrm{mM}$ MES pH 5.7 and $10 \mathrm{mM} \mathrm{MgCl}_{2}$ at an $\mathrm{OD}_{600}$ of 0.5 . Four to sixweek-old leaves of Nicotiana tabaccum were gently infiltrated with the homogenous bacterial suspension using $1 \mathrm{ml}$ syringe, without needle, from the abaxial surface. These leaves were plucked 4 to 7 days after infiltration and tested for GUS activity using 5-bromo-4-chloro-3-indolyl glucuronide (X-gluc) as a substrate in a buffer containing $100 \mathrm{mM}$ Sodium phosphate $\mathrm{pH} 7.0,0.5 \mathrm{mM}$ Potassium ferrocyanide, $0.5 \mathrm{mM}$ Potassium ferricyanide, $0.05 \%$ Triton-X-100 and $1 \mathrm{mg} \mathrm{ml}{ }^{-1}$ $\mathrm{X}$-gluc ${ }^{21}$.

Protein-protein interaction in vivo. Using immunoaffinity pulldown, we studied protein-protein interactions between Osa and VirB/D4 T4SS components. Various strains of Agrobacterium tumefaciens were used for this purpose. Here WT refers to A348. A348 is aC58 strain harbouring the octopine-type pTiA6NC plasmid. A348 derivatives include Mx355 ( $\Delta$ virD4) and PC1004 ( $\Delta$ virB4). A136 (A \& G) is a C58 strain cured of pTiA6NC plasmid harbouring virA of pTiA6NC and virG of pTiBo542 on its circular chromosome ${ }^{68}$. All A. tumefaciens strains were grown in $\mathrm{LB}$ supplemented with glutamate and mannitol at $28^{\circ} \mathrm{C}$. Conditions for induction of the A. tumefaciens vir genes have been described previously ${ }^{69}$. When required, vir-induction medium was supplemented with antibiotics (in $\mu \mathrm{g} \mathrm{ml}^{-1}$ ) as follows: gentamicin (100), tetracycline (5) and carbenicillin (100). Initially, we induced and expressed FLAG-Osa (from pKA197) in $500 \mathrm{ml}$ of A. tumefaciens WT strain A348. Cells were then harvested, lysed by french cell-press treatment and membrane extracts isolated. Two mg of total membrane was then solubilized with $\mathrm{N}, \mathrm{N}$ Dimethyldodecylamine N-oxide in $50 \mathrm{mM}$ Tris- $\mathrm{HCl}$, pH 7.4 and $1 \mathrm{mM}$ EDTA, at $4{ }^{\circ} \mathrm{C}$ for $\mathrm{O} / \mathrm{N}$ with gentle rocking. After centrifuging the solubilized material at $15,000 \mathrm{~g}$ for $15 \mathrm{~min}$, we used the supernatant and evaluated for Osa interacting partners by co-immunoprecipitation with either antibodies to VirB2 to VirB11, VirC1, VirC2, VirE1, VirE2, VirD1, VirD2 and VirD4 proteins or FLAG-tag. Proteins were resolved by SDS-PAGE as previously described. Vir proteins were transferred to nitrocellulose and later developed with goat anti-rabbit secondary antibodies conjugated to alkaline phosphatase (Supplementary Fig. 6). Since we observed only VirB4 and VirB11 proteins interacting with FLAG-Osa (Fig. 4a,b), we further analysed if these interactions were more direct. Consequently, we induced and expressed FLAG-Osa in $\Delta v i r B 4, \Delta v i r D 4$ and $\mathrm{A} 136(\mathrm{~A}+\mathrm{G})$ strains. A136 (A + G) also expressed either VirB4 (pKA93) Fig. 4a or VirB11 Fig. 4b (pSR45) (ref. 31).

Protein-protein interaction in vitro. Purified proteins, Osa and ICE1056Fin, were blotted onto nitrocellulose membrane using a slot-blot manifold blocked with 5\% BSA at $4{ }^{\circ} \mathrm{C}$ for $1 \mathrm{~h}$, washed thrice with PBS containing $0.05 \%$ Tween-20 (PBS-T), followed by three washes with PBS for 5 min each. MBP-tagged purified $A$. tumefaciens T4SS and relaxosome components-VirD4, VirB11, VirB4 and VirCl were incubated with immobilized proteins. This was followed by three washes with PBS-T and then three washes with PBS. Horseradish peroxidase-conjugated antiMBP antibodies, reconstituted in $15 \mathrm{ml}$ of PBS containing $10 \mathrm{mM} \mathrm{MgCl}_{2}$, was added to the blot and incubated for $30 \mathrm{~min}$, followed by three PBS-T washes and three PBS washes, each for $5 \mathrm{~min}$. Blots were developed with 3,3'-diaminobenzidine tetrahydrochloride (Supplementary Fig. 6).

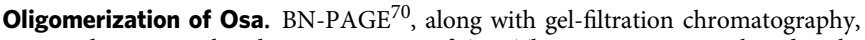
was used to assess the oligomeric status of Osa. The protein was incubated with loading buffer for $10 \mathrm{~min}$ at room temperature and loaded onto 4 to $20 \%$ gradient native PAGE. The gel was run at $100 \mathrm{~V}$ at $4{ }^{\circ} \mathrm{C}$. Anode and cathode buffers had the following composition: $100 \mathrm{mM}$ Tris pH 8.0, 40\% Glycerol, $0.5 \%$ Coomassie Brilliant Blue-G250; $100 \mathrm{mM}$ Tris-HCl pH 8.8; and $100 \mathrm{mM}$ Histidine $(\mathrm{pH}$ adjusted to 8.0 using Tris base), $0.02 \%$ Coomassie Brilliant Blue-G250, respectively. After the gel was run two-thirds of its length, the cathode buffer was replaced with fresh buffer without the dye. Gel was stained with Coomassie Brilliant Blue R-250 and then destained, as done for regular SDS-PAGE.

T-DNA-VirD2 complex preparation. Fifteen picomoles of 90-mer oligonucleotides (Macrogen) with and without T-DNA left border (LB) and right border (RB) were labelled at the $3^{\prime}$ end using $30 \mu \mathrm{Ci}\left[\alpha-\mathrm{P}^{32}\right] \mathrm{dCTP}$ and terminal transferase. The labelling reaction was carried out for $15 \mathrm{~min}$ at $37^{\circ} \mathrm{C}$ followed by purification through Illustra MicroSpin G-25 Columns (GE). The purified labelled oligos were quantified for labelling efficiency by measuring the counts in scintillation counter. RB containing $3^{\prime}$ labelled oligo (15 pmol) was covalently attached to VirD2 $(100 \mathrm{pmol})$ at the $5^{\prime}$ end by incubating the mixture at $37^{\circ} \mathrm{C}$ for $4 \mathrm{~h}$ in a reaction buffer containing $20 \mathrm{mM}$ Tris- $\mathrm{HCl} \mathrm{pH} 8.8,50 \mathrm{mM} \mathrm{NaCl}$ and $5 \mathrm{mM} \mathrm{MgCl}_{2}$. Products containing 30,000 counts were loaded onto gradient TAE-PAGE (4-16\%) gels using $1 \times$ SDS-PAGE loading dye to check the site-specific covalent modification of oligo by VirD2 and then used in FIN reconstitution.

FIN reconstitution. Covalently linked T-DNA-VirD2 substrate complex was made using the above protocol. Cytoplasmic complex of the T4SS was reconstituted by mixing VirB4 and VirB11 in 1:1:1 molar ratio, by adding $30 \mathrm{fmol}$ of each protein This mixture was dialyzed into a buffer containing $25 \mathrm{mM}$ Tris $\mathrm{pH} 8.0,100 \mathrm{mM}$ $\mathrm{NaCl}$ and $2 \mathrm{mM}$ DTT for $2 \mathrm{~h}$. DNase reaction was set up with radiolabeled VirD2.T-DNA complex (30,000 counts; $30 \mathrm{fmol})$ in nuclease buffer. Osa and Osapenta were added to this reconstituted complex, to the final concentration of 3.8, 7.6 and $38 \mu \mathrm{mol}$. The reaction mixture was incubated for $6 \mathrm{~h}$ at $37^{\circ} \mathrm{C}$ and the products were run on 4-16\% gradient TAE-PAGE, detected using phosphor imager, after exposure for $2 \mathrm{~h}$. We observed that higher amounts of Osa is required to cleave T-DNA linked to VirD2 and also when T4SS ATPases are present, compared with naked DNA. This is likely to be due to stoichiometric interactions influencing nuclease activity of Osa in vitro.

\section{References}

1. Dionisio, F., Conceicao, I. C., Marques, A. C., Fernandes, L. \& Gordo, I. The evolution of a conjugative plasmid and its ability to increase bacterial fitness. Biol. Lett. 1, 250-252 (2005).

2. Fernandez-Lopez, R. et al. Dynamics of the IncW genetic backbone imply general trends in conjugative plasmid evolution. FEMS Microbiol. Rev. 30, 942-966 (2006).

3. Christie, P. J., Atmakuri, K., Krishnamoorthy, V., Jakubowski, S. \& Cascales, E. Biogenesis, architecture, and function of bacterial type IV secretion systems. Annu. Rev. Microbiol. 59, 451-485 (2005).

4. Schroder, G. \& Lanka, E. The mating pair formation system of conjugative plasmids-A versatile secretion machinery for transfer of proteins and DNA. Plasmid 54, 1-25 (2005).

5. de la Cruz, F., Frost, L. S., Meyer, R. J. \& Zechner, E. L. Conjugative DNA metabolism in Gram-negative bacteria. FEMS Microbiol. Rev. 34, 18-40 (2010)

6. Zechner, E. L., Lang, S. \& Schildbach, J. F. Assembly and mechanisms of bacterial type IV secretion machines. Philos. Trans. R. Soc. Lond. B Biol. Sci. 367, 1073-1087 (2012)

7. Alvarez-Martinez, C. E. \& Christie, P. J. Biological diversity of prokaryotic type IV secretion systems. Microbiol. Mol. Biol. Rev. 73, 775-808 (2009).

8. Cascales, E. \& Christie, P. J. Definition of a bacterial type IV secretion pathway for a DNA substrate. Science 304, 1170-1173 (2004).

9. Trokter, M., Felisberto-Rodrigues, C., Christie, P. J. \& Waksman, G. Recent advances in the structural and molecular biology of type IV secretion systems. Curr. Opin. Struct. Biol. 27C, 16-23 (2014).

10. Zupan, J. R. \& Zambryski, P. Transfer of T-DNA from Agrobacterium to the plant cell. Plant Physiol. 107, 1041-1047 (1995).

11. Fong, S. T. \& Stanisich, V. A. Location and characterization of two functions on RP1 that inhibit the fertility of the IncW plasmid R388. J. Gen. Microbiol. 135, 499-502 (1989)

12. Olsen, R. H. \& Shipley, P. L. RP1 properties and fertility inhibition among P, N, W, and X incompatibility group plasmids. J. Bacteriol. 123, 28-35 (1975).

13. Santini, J. M. \& Stanisich, V. A. Both the fipA gene of pKM101 and the pifC gene of $\mathrm{F}$ inhibit conjugal transfer of RP1 by an effect on traG. J. Bacteriol. 180, 4093-4101 (1998).

14. Chen, C. Y. \& Kado, C. I. Inhibition of Agrobacterium tumefaciens oncogenicity by the osa gene of pSa. J. Bacteriol. 176, 5697-5703 (1994).

15. Close, S. M. \& Kado, C. I. The osa gene of pSa encodes a 21.1-kilodalton protein that suppresses Agrobacterium tumefaciens oncogenicity. J. Bacteriol. 173, 5449-5456 (1991).

16. Cascales, E., Atmakuri, K., Liu, Z., Binns, A. N. \& Christie, P. J. Agrobacterium tumefaciens oncogenic suppressors inhibit T-DNA and VirE2 protein substrate binding to the VirD4 coupling protein. Mol. Microbiol. 58, 565-579 (2005).

17. Lee, L. Y. \& Gelvin, S. B. Osa protein constitutes a strong oncogenic suppression system that can block vir-dependent transfer of IncQ plasmids between Agrobacterium cells and the establishment of IncQ plasmids in plant cells. J. Bacteriol. 186, 7254-7261 (2004).

18. Lee, L.-Y., Gelvin, S. B. \& Kado, C. I. pSa causes oncogenic suppression of Agrobacterium by inhibiting VirE2 protein export. J. Bacteriol. 181, 186-196 (1999).

19. Holm, L. \& Rosenstrom, P. Dali server: conservation mapping in 3D. Nucleic Acids Res. 38, W545-W549 (2010).

20. Sparkes, I. A., Runions, J., Kearns, A. \& Hawes, C. Rapid, transient expression of fluorescent fusion proteins in tobacco plants and generation of stably transformed plants. Nat. Protoc. 1, 2019-2025 (2006) 
21. Jefferson, R. A., Kavanagh, T. A. \& Bevan, M. W. GUS fusions: betaglucuronidase as a sensitive and versatile gene fusion marker in higher plants. EMBO J. 6, 3901-3907 (1987).

22. Juhas, M. et al. Sequence and functional analyses of Haemophilus spp. genomic islands. Genome Biol. 8, R237 (2007).

23. Shaw, N. et al. Crystal structure solution of a ParB-like nuclease at atomic resolution. Proteins 70, 263-267 (2008).

24. Chi, Y. H. et al. Dual functions of Arabidopsis sulfiredoxin: acting as a redoxdependent sulfinic acid reductase and as a redox-independent nuclease enzyme. FEBS Lett. 586, 3493-3499 (2012).

25. Jonsson, T. J., Murray, M. S., Johnson, L. C., Poole, L. B. \& Lowther, W. T. Structural basis for the retroreduction of inactivated peroxiredoxins by human sulfiredoxin. Biochemistry 44, 8634-8642 (2005).

26. Park, J. W., Mieyal, J. J., Rhee, S. G. \& Chock, P. B. Deglutathionylation of 2-Cys peroxiredoxin is specifically catalyzed by sulfiredoxin. J. Biol. Chem. 284, 23364-23374 (2009).

27. Hwang, L. C. et al. ParA-mediated plasmid partition driven by protein pattern self-organization. EMBO J. 32, 1238-1249 (2013).

28. Kusiak, M., Gapczynska, A., Plochocka, D., Thomas, C. M. \& Jagura-Burdzy, G. Binding and spreading of ParB on DNA determine its biological function in Pseudomonas aeruginosa. J. Bacteriol. 193, 3342-3355 (2011).

29. Schumacher, M. A. \& Funnell, B. E. Structures of ParB bound to DNA reveal mechanism of partition complex formation. Nature 438, 516-519 (2005).

30. Chen, C. Y. \& Kado, C. I. Osa protein encoded by plasmid pSa is located at the inner membrane but does not inhibit membrane association of VirB and VirD virulence proteins in Agrobacterium tumefaciens. FEMS Microbiol. Lett. 135, 85-92 (1996).

31. Atmakuri, K., Cascales, E. \& Christie, P. J. Energetic components VirD4, VirB11 and VirB4 mediate early DNA transfer reactions required for bacterial type IV secretion. Mol. Microbiol. 54, 1199-1211 (2004).

32. Jasper, F., Koncz, C., Schell, J. \& Steinbiss, H. H. Agrobacterium T-strand production in vitro: sequence-specific cleavage and $5^{\prime}$ protection of singlestranded DNA templates by purified VirD2 protein. Proc. Natl Acad. Sci. USA 91, 694-698 (1994).

33. Durrenberger, F., Crameri, A., Hohn, B. \& Koukolikova-Nicola, Z. Covalently bound VirD2 protein of Agrobacterium tumefaciens protects the T-DNA from exonucleolytic degradation. Proc. Natl Acad. Sci. USA 86, 9154-9158 (1989).

34. Atmakuri, K., Cascales, E., Burton, O. T., Banta, L. M. \& Christie, P. J. Agrobacterium ParA/MinD-like VirC1 spatially coordinates early conjugative DNA transfer reactions. EMBO J. 26, 2540-2551 (2007).

35. Guo, M., Jin, S., Sun, D., Hew, C. L. \& Pan, S. Q. Recruitment of conjugative DNA transfer substrate to Agrobacterium type IV secretion apparatus. Proc. Natl Acad. Sci. USA 104, 20019-20024 (2007).

36. Schrammeijer, B., den Dulk-Ras, A., Vergunst, A. C., Jurado Jacome, E. \& Hooykaas, P. J. Analysis of Vir protein translocation from Agrobacterium tumefaciens using Saccharomyces cerevisiae as a model: evidence for transport of a novel effector protein VirE3. Nucleic Acids Res. 31, 860-868 (2003).

37. Miller, J. F., Lanka, E. \& Malamy, M. H. F factor inhibition of conjugal transfer of broad-host-range plasmid RP4: requirement for the protein product of pif operon regulatory gene pifC. J. Bacteriol. 163, 1067-1073 (1985).

38. Aravind, L. Guilt by association: contextual information in genome analysis. Genome Res. 10, 1074-1077 (2000).

39. Gabaldon, T. \& Huynen, M. A. Prediction of protein function and pathways in the genome era. Cell. Mol. Life Sci. 61, 930-944 (2004).

40. Adamczyk, M., Dolowy, P., Jonczyk, M., Thomas, C. M. \& Jagura-Burdzy, G. The kfrA gene is the first in a tricistronic operon required for survival of IncP-1 plasmid R751. Microbiology 152, 1621-1637 (2006).

41. Anantharaman, V. \& Aravind, L. New connections in the prokaryotic toxinantitoxin network: relationship with the eukaryotic nonsense-mediated RNA decay system. Genome Biol. 4, R81 (2003).

42. Mutschler, H., Gebhardt, M., Shoeman, R. L. \& Meinhart, A. A novel mechanism of programmed cell death in bacteria by toxin-antitoxin systems corrupts peptidoglycan synthesis. PLoS Biol. 9, e1001033 (2011).

43. Anantharaman, V., Makarova, K. S., Burroughs, A. M., Koonin, E. V. \& Aravind, L. Comprehensive analysis of the HEPN superfamily: identification of novel roles in intra-genomic conflicts, defense, pathogenesis and RNA processing. Biol. Direct 8, 15 (2013).

44. Kinch, L. N., Yarbrough, M. L., Orth, K. \& Grishin, N. V. Fido, a novel AMPylation domain common to fic, doc, and AvrB. PLoS ONE 4, e5818 (2009).

45. Anantharaman, V., Iyer, L. M. \& Aravind, L. Ter-dependent stress response systems: novel pathways related to metal sensing, production of a nucleosidelike metabolite, and DNA-processing. Mol. Biosyst. 8, 3142-3165 (2012).

46. Jonsson, T. J., Johnson, L. C. \& Lowther, W. T. Structure of the sulphiredoxinperoxiredoxin complex reveals an essential repair embrace. Nature 451, 98-101 (2008).

47. Zhang, D., de Souza, R. F., Anantharaman, V., Iyer, L. M. \& Aravind, L. Polymorphic toxin systems: comprehensive characterization of trafficking modes, processing, mechanisms of action, immunity and ecology using comparative genomics. Biol. Direct 7, 18 (2012).

48. Iyer, L. M., Zhang, D., Burroughs, A. M. \& Aravind, L. Computational identification of novel biochemical systems involved in oxidation, glycosylation and other complex modifications of bases in DNA. Nucleic Acids Res. 41, 7635-7655 (2013).

49. Wang, L. et al. Phosphorothioation of DNA in bacteria by dnd genes. Nat. Chem. Biol. 3, 709-710 (2007).

50. Ptacin, J. L. et al. A spindle-like apparatus guides bacterial chromosome segregation. Nat. Cell Biol. 12, 791-798 (2010).

51. Scholefield, G., Whiting, R., Errington, J. \& Murray, H. Spo0J regulates the oligomeric state of Soj to trigger its switch from an activator to an inhibitor of DNA replication initiation. Mol. Microbiol. 79, 1089-1100 (2011).

52. Vecchiarelli, A. G., Hwang, L. C. \& Mizuuchi, K. Cell-free study of F plasmid partition provides evidence for cargo transport by a diffusion-ratchet mechanism. Proc. Natl Acad. Sci. USA 110, E1390-E1397 (2013).

53. Autret, S., Nair, R. \& Errington, J. Genetic analysis of the chromosome segregation protein Spo0J of Bacillus subtilis: evidence for separate domains involved in DNA binding and interactions with Soj protein. Mol. Microbiol. 41, 743-755 (2001).

54. Berger, B. R. \& Christie, P. J. The Agrobacterium tumefaciens virB4 gene product is an essential virulence protein requiring an intact nucleoside triphosphate-binding domain. J. Bacteriol. 175, 1723-1734 (1993).

55. Chen, C. Y., Wang, L. \& Winans, S. C. Characterization of the supervirulent virG gene of the Agrobacterium tumefaciens plasmid pTiBo542. Mol. Gen. Genet. 230, 302-309 (1991).

56. Otwinowski, Z. \& Minor, W. Processing of X-ray Diffraction Data Collected in Oscillation Mode (Academic Press, 1997).

57. Sheldrick, G. M. A short history of SHELX. Acta Crystallogr. A 64, 112-122 (2008).

58. Cowtan, K. The Buccaneer software for automated model building. 1. Tracing protein chains. Acta Crystallogr. D Biol. Crystallogr. 62, 1002-1011 (2006).

59. Winn, M. D. et al. Overview of the CCP4 suite and current developments. Acta Crystallogr. D Biol. Crystallogr. 67, 235-242 (2011).

60. Emsley, P. \& Cowtan, K. Coot: model-building tools for molecular graphics. Acta Crystallogr. D Biol. Crystallogr. 60, 2126-2132 (2004).

61. Adams, P. D. et al. PHENIX: a comprehensive Python-based system for macromolecular structure solution. Acta Crystallogr. D Biol. Crystallogr. 66, 213-221 (2010).

62. Laskowski, R. A., MacArthur, M. W., Moss, D. S. \& Thornton, J. M. PROCHECK: a program to check the stereochemical quality of protein structures. J. Appl. Crystallogr. 26, 283-291 (1993).

63. Pettersen, E. F. et al. UCSF Chimera-a visualization system for exploratory research and analysis. J. Comput. Chem. 25, 1605-1612 (2004).

64. Altschul, S. F. et al. Gapped BLAST and PSI-BLAST: a new generation of protein database search programs. Nucleic Acids Res. 25, 3389-3402 (1997)

65. Finn, R. D., Clements, J. \& Eddy, S. R. HMMER web server: interactive sequence similarity searching. Nucleic Acids Res. 39, W29-W37 (2011).

66. Lassmann, T., Frings, O. \& Sonnhammer, E. L. Kalign2: high-performance multiple alignment of protein and nucleotide sequences allowing external features. Nucleic Acids Res. 37, 858-865 (2009).

67. Pansegrau, W., Schoumacher, F., Hohn, B. \& Lanka, E. Site-specific cleavage and joining of single-stranded DNA by VirD2 protein of Agrobacterium tumefaciens Ti plasmids: analogy to bacterial conjugation. Proc. Natl Acad. Sci. USA 90, 11538-11542 (1993).

68. Ding, Z. et al. A novel cytology-based, two-hybrid screen for bacteria applied to protein-protein interaction studies of a type IV secretion system. J. Bacteriol. 184, 5572-5582 (2002).

69. Zhou, X. R. \& Christie, P. J. Mutagenesis of the Agrobacterium VirE2 singlestranded DNA-binding protein identifies regions required for self-association and interaction with VirE1 and a permissive site for hybrid protein construction. J. Bacteriol. 181, 4342-4352 (1999).

70. Niepmann, M. \& Zheng, J. Discontinuous native protein gel electrophoresis. Electrophoresis 27, 3949-3951 (2006).

\section{Acknowledgements}

We thank Amit Sharma and Sunil Mukherjee (ICGEB) for providing access to infrastructure, green house, plants and help with agroinfiltration, Nirupam Roy Choudary (ICGEB) for help with TLC experiments, K. Veluthambi and Hussain Munnavar (Madurai Kamaraj University) for Agrobacterium strains and plasmids and P1 genomic DNA, respectively, Derrick Crook (University of Oxford) for ICEHin1056 DNA, Bichitra K. Biswal and Ravikant Pal (National Institute of Immunology, New Delhi) for access to X-ray data collection facility, funded by DBT, India, S. Krishnaswamy (Madurai Kamaraj University), Anmol and Sujatha, (ICGEB) for suggestions and critical reading of the manuscript. P.M., P.G. and R.R. are supported by CSIR fellowship. A.O. and S.G. are supported by DBT fellowship. L.A. and L.M.I. are supported by funds of the intramural research programme of the National Library of Medicine, NIH. Work in the Christie laboratory is supported by NIH grant R01GM48746. A.A. is supported by funding from 
DBT (Basic Research in Modern Biology Task Force and Rapid Grant for Young Investigators) and ICGEB core fund.

\section{Author contributions}

P.G., P.M. and A.A. purified and crystallized Osa. P.G. and A.A. solved the structure and P.M. performed the refinement. L.M.I. and L.A. carried out computational analysis, fold and functional site prediction. P.M. and R.R. planned and carried out mutagenesis, protein expression and purification, in planta bioassays, biochemical experiments and the reconstitution studies. R.R. contributed to every experimental data presented here, except structure determination and in vivo immunoaffinity pull downs. A.O. and S.G. helped in cloning, expression and purification of few proteins and their contributions were equal. K.A. and P.J.C. generated Osa overexpression construct and carried out co-immunoprecipitation in vivo. K.A. and L.M.I. gave inputs for experiments. P.M., R.R., K.A., L.M.I., L.A. and A.A. wrote the manuscript from inputs from other authors. A.A. conceived, planned and orchestrated the project.

\section{Additional information}

Accession codes: PDB coordinates: The atomic coordinates of Osa native and derivative have been deposited in the Protein Data Bank under accession numbers $4 \mathrm{O} 7 \mathrm{~K}$ and $4 \mathrm{OVB}$, respectively.

Supplementary Information accompanies this paper at http://www.nature.com/ naturecommunications

Competing financial interests: The authors declare no competing financial interests.

Reprints and permission information is available online at http://npg.nature.com/ reprintsandpermissions/

How to cite this article: Maindola, P. et al. Multiple enzymatic activities of ParB/Srx superfamily mediate sexual conflict among conjugative plasmids. Nat. Commun. 5:5322 doi: $10.1038 /$ ncomms6322 (2014). 